\title{
Associations of Trying to Lose Weight, Weight Control Behaviors, and Current Cigarette Use Among US High School Students
}

\author{
JONETTA L. JOHNSON, MPH \\ Danice K. EATON, MPH, PhD \\ Linda L. Pederson, PhD \\ RICHARD LOWRY, MD, MS
}

\begin{abstract}
BACKGROUND: Approximately one-quarter of high school students currently use cigarettes. Previous research has suggested some youth use smoking as a method for losing weight. The purpose of this study was to describe the association of current cigarette use with specific healthy and unhealthy weight control practices among 9th-12th grade students in the United States.
\end{abstract}

METHODS: Youth Risk Behavior Survey data (2005) were analyzed. Behaviors included current cigarette use, trying to lose weight, and current use of 2 healthy and 3 unhealthy behaviors to lose weight or to keep from gaining weight. Separate logistic regression models calculated adjusted odds ratios (AORs) for associations of current cigarette use with trying to lose weight (Model 1) and the 5 weight control behaviors, controlling for trying to lose weight (Model 2).

RESULTS: In Model 1, compared with students who were not trying to lose weight, students who were trying to lose weight had higher odds of current cigarette use ( $A O R=$ 1.30, 95\% Cl: 1.15-1.49). In Model 2, the association of current cigarette use with the 2 healthy weight control behaviors was not statistically significant. Each of the 3 unhealthy weight control practices was significantly associated with current cigarette use, with AORs for each behavior approximately 2 times as high among those who engaged in the behavior, compared with those who did not.

CONCLUSION: Some students may smoke cigarettes as a method of weight control. Inclusion of smoking prevention messages into existing weight management interventions may be beneficial.

Keywords: nutrition and diet; smoking and tobacco; risk behaviors.

Citation: Johnson JL, Eaton DK, Pederson LL, Lowry R. Associations of trying to lose weight, weight control behaviors, and current cigarette use among US high school students. J Sch Health. 2009; 79: 355-360.

Accepted March 29, 2009

\footnotetext{
a At the time this study was conducted, the author was an ASPH Fellow in SERB/DASH/NCCDPHP/CDC. Currently, the author is a PhD Student (jonettaj@umich.edu), Department of Health Behavior and Health Education, University of Michigan School of Public Health, 109 South Observatory Street, SPHI, Ann Arbor, Ml 48109.

bCommander, (DEaton@cdc.gov), United States Public Health Service, SERB/DASH/NCCDPHP/CDC, 4770 Buford Highway NE, MS K-33, Atlanta, GA 30341.

cSenior Scientific Advisor, (lindap@mindspring.com), Health Communications Branch Senior Service, Office on Smoking and Health, Centers for Disease Control and Prevention, 4770 Buford Highway NE, MS K-50, Atlanta, GA 30341

dMedical Epidemiologist, (rxl1@acdc.gov), SERB/DASH/NCCDPHP/CDC, 4770 Buford Highway NE, MS K-33, Atlanta, GA 30341.

Address correspondence to: Jonetta L. Johnson, (jonettaj@umich.edu), Department of Health Behavior and Health Education, University of Michigan School of Public Health, 109 South Observatory Street, SPHI, Ann Arbor, MI 48109.

The findings and conclusions in this report are those of the authors and do not necessarily represent the views of the Centers for Disease Control and Prevention.

This article is a US Government work and is in the public domain in the USA.
} 
$\mathrm{A}$ lthough lifetime and current cigarette use among high school students declined during 1999-2003, it remained unchanged during 2003-2005. ' Because nearly one-quarter of high school students report current cigarette use, ${ }^{2}$ significant progress needs to be made to achieve the Healthy People 2010 objective to reduce current cigarette use among high school students to $<16 \%{ }^{3}$ Understanding adolescent motivation may help to reduce cigarette use.

Among adolescents, weight control may be one of several perceived benefits of cigarette use. Indeed, previous research has shown associations between smoking and trying to lose weight, particularly among female adolescents. ${ }^{4-11}$ For example, Delveno et al found that female high school students who smoked were more likely to report intentions to lose weight when compared with nonsmokers. 9 Studies of the association between cigarette use and trying to lose weight that include both male and female adolescents produce inconsistent findings: some show no association among males, 4,12 and others show significant associations among both males and females. ${ }^{13,14}$ Variation by race/ethnicity also has been found. With the exception of black females, Fulkerson found that adolescent female smokers of nonwhite and multiple racial/ethnic groups were as likely as white adolescent females to smoke to lose or control weight. ${ }^{14}$ In addition, Asian American and American Indian adolescent males were more likely than white adolescent males to smoke to lose or control weight, whereas black, Hispanic, and multiple race adolescent males were as likely as white adolescent males to smoke to lose or control weight. ${ }^{14}$

Several studies examine the relationship of smoking to specific weight control behaviors, including healthy behaviors (dieting and exercise) and unhealthy behaviors (vomiting; fasting; binge and purge behavior; and laxative, diet pill, and diuretic use). 7,9,12,15-17 For example, Neumark-Sztainer and Hannan found cigarette use significantly associated with dieting and binging and purging behavior among girls, though not among boys, ${ }^{12}$ whereas Lowry et al found associations between smoking and healthy weight control behaviors (exercising) among male students and unhealthy weight control behaviors (fasting, taking diet pills, and vomiting or using laxatives) among male and female students. ${ }^{7}$ We did not locate any published studies that examined racial/ethnic differences in the association between smoking and weight control behaviors.

Although associations between cigarette use and trying to lose weight and specific weight control behaviors have been examined previously, these associations have not been tested to identify whether each behavior is independently associated with cigarette use. As a result, it is unclear whether trying to lose weight is an independent risk factor for cigarette use or whether trying to lose weight is merely a proxy for specific healthy or unhealthy weight control behaviors that are directly associated with cigarette use. In addition, actual body weight and perceptions of body weight may be confounders in the association between trying to lose weight and cigarette use, ${ }^{14}$ but most studies do not control for these factors. $7,9,13,15,17$ The purpose of this study is to address shortcomings in the literature concerning 9 th -12 th grade students by testing (1) whether trying to lose weight and specific healthy and unhealthy weight control behaviors are independently associated with current cigarette use, while controlling for body mass index (BMI) and perceived weight and (2) whether these associations vary by sex or race/ethnicity.

\section{METHODS}

\section{Sample and Survey Administration}

The national school-based Youth Risk Behavior Survey, implemented by the Centers for Disease Control and Prevention (CDC) and approved by an institutional review board at the $\mathrm{CDC}$, monitors the prevalence of priority health risk behaviors among youth. In spring 2005, a 3-stage, cluster-sample design was used to obtain a nationally representative sample of students in grades 9-12. Parental permission was obtained before survey administration in accordance with local procedures, and participation in the survey was voluntary. Students completed anonymously the self-administered, 98-item questionnaire in their classrooms during a regular class period and recorded their responses directly onto a computer-scannable booklet or answer sheet.

The sampling strategy has been described elsewhere. ${ }^{18,19}$ The school response rate was $78 \%$, the student response rate $86 \%$, and the overall response rate $67 \%$. Usable questionnaires were returned by 13,917 students. A weighting factor was applied to each student record to adjust for nonresponse and the oversampling of black and Hispanic students.

\section{Procedures}

Student demographic characteristics included sex, grade (9th, 10th, 11 th, or 12 th), and race and ethnicity (non-Hispanic white, non-Hispanic black, Hispanic, or other). Current cigarette use was measured by the question, "During the past 30 days, on how many days did you smoke cigarettes?" Response options were collapsed dichotomously as 0 days or $\geq 1$ day. Trying to lose weight was measured by the question, "Which of the following are you trying to do about your weight?" Response options were collapsed to create 2 categories, "lose weight," or all other options (i.e., "gain weight," "stay the same weight," or "I am not trying to do anything about my weight"). Because results from this study can add to the existing literature, current cigarette use and trying to lose weight were 
dichotomized in the manner described to be consistent with previously published studies on this topic.

Two healthy weight control behaviors were assessed by the following questions: "During the past 30 days, did you eat less food, fewer calories, or foods low in fat to lose weight or to keep from gaining weight?" (ate less food, fewer calories, or foods low in fat) and "During the past 30 days, did you exercise to lose weight or to keep from gaining weight?" (exercise). Three unhealthy weight control behaviors were assessed by the following questions: "During the past 30 days, did you go without eating for 24 hours or more (also called fasting) to lose weight or to keep from gaining weight?" (went without eating for $\geq$ 24 hours); "During the past 30 days, did you take any diet pills, powders, or liquids without a doctor's advice to lose weight or to keep from gaining weight? (Do not include meal replacement products such as Slim Fast)" (took diet pills, powders, or liquids); and "During the past 30 days, did you vomit or take laxatives to lose weight or to keep from gaining weight?" (vomited or took laxatives). Response options for all 5 weight control behavior questions were "yes" or "no."

BMI (calculated as weight in kilograms divided by the square of height in meters) was calculated from the metric conversion of self-reported height in inches and weight in pounds. Using CDC growth charts as a reference, ${ }^{2,20}$ a 5-level categorical variable was created on the basis of the BMI percentile for age and sex. The 5 categories were underweight $(\leq 5$ th percentile), at risk for underweight (6th-15th percentile), normal weight (16th-84th percentile), at risk for overweight (85th-94th percentile), and overweight ( $\geq 95$ th percentile). Perceived weight was measured by the question, "How do you describe your weight?" Response options were "very underweight," "slightly underweight," "about the right weight," "slightly overweight," and "very overweight."

\section{Data Analysis}

All statistical analyses, including prevalence estimates, adjusted odds ratios (AORs), and corresponding $95 \%$ confidence intervals, were performed on weighted data using SAS-Callable SUDAAN ${ }^{2},{ }^{21}$ a statistical software package that accounts for the complex sampling design. Two logistic regression models were run: Model 1 calculated the association between trying to lose weight and current cigarette use and Model 2 calculated the association between the 5 weight control behaviors and current cigarette use, controlling for trying to lose weight. All models controlled for sex, race/ethnicity, grade, perceived weight, and BMI category. AORs were considered significant if the corresponding 95\% confidence intervals did not include 1.0.

Interaction terms were added to Model 2 to test whether the association between the independent variables (trying to lose weight and the 5 weight control behaviors) and the dependent variable (current cigarette use) varied by sex and race/ethnicity. An interaction term for each pairwise combination of demographic variable with independent variable (e.g., sex $\times$ trying to lose weight) was created and entered simultaneously into the model. An interaction was considered statistically significant if its corresponding Wald statistic p-value was <.05.

\section{RESULTS}

Table 1 reports the prevalence of demographic characteristics, current cigarette use, trying to lose weight,

Table 1. Prevalence of Demographic Characteristics, Current Cigarette Use, Trying to Lose Weight, and Weight Control Behaviors Among US High School Students - United States, 2005

\begin{tabular}{|c|c|c|}
\hline & $\%$ & $95 \% \mathrm{Cl} \pm$ \\
\hline \multicolumn{3}{|l|}{ Demographic characteristics } \\
\hline \multicolumn{3}{|l|}{ Sex } \\
\hline Female & 49.5 & 1.0 \\
\hline Male & 50.5 & 1.0 \\
\hline \multicolumn{3}{|l|}{ Race/ethnicity } \\
\hline White* & 61.9 & 4.0 \\
\hline Black* & 14.6 & 2.6 \\
\hline Hispanic & 15.1 & 1.8 \\
\hline Other & 8.3 & 2.0 \\
\hline \multicolumn{3}{|l|}{ Grade } \\
\hline $9^{\text {th }}$ & 29.1 & 1.4 \\
\hline $10^{\text {th }}$ & 25.9 & 1.0 \\
\hline $11^{\text {th }}$ & 23.3 & 1.0 \\
\hline $12^{\text {th }}$ & 21.7 & 1.3 \\
\hline \multicolumn{3}{|l|}{ BMI } \\
\hline Underweight & 2.1 & 0.3 \\
\hline At risk for underweight & 4.6 & 0.5 \\
\hline Normal & 64.6 & 1.4 \\
\hline At risk for overweight & 15.7 & 0.9 \\
\hline Overweight & 13.1 & 0.9 \\
\hline \multicolumn{3}{|l|}{ Perceived weight } \\
\hline Very underweight & 1.9 & 0.4 \\
\hline Slightly underweight & 12.2 & 0.8 \\
\hline About the right weight & 54.4 & 1.3 \\
\hline Slightly overweight & 26.9 & 0.9 \\
\hline Very overweight & 4.6 & 0.6 \\
\hline Current cigarette use $^{\dagger}$ & 23.0 & 2.3 \\
\hline Trying to lose weight & 45.6 & 1.2 \\
\hline \multicolumn{3}{|l|}{ Healthy weight control behaviors } \\
\hline Exercised $^{\ddagger}$ & 60.0 & 1.4 \\
\hline Ate less food, fewer calories, or foods low in fat ${ }^{\ddagger}$ & 40.7 & 1.2 \\
\hline \multicolumn{3}{|l|}{ Unhealthy weight control behaviors } \\
\hline Went without eating for $\geq 24$ hours $^{\ddagger}$ & 12.3 & 0.9 \\
\hline Took diet pills, powders, or liquids ${ }^{\ddagger}$ & 6.3 & 1.0 \\
\hline Vomited or took laxatives ${ }^{\ddagger}$ & 4.5 & 0.5 \\
\hline
\end{tabular}

*Non-Hispanic

${ }^{\dagger}$ Smoked cigarettes on $\geq 1$ of the 30 days preceding the survey.

₹To lose weight or to keep from gaining weight during the 30 days preceding the survey.

$\mathrm{BMI}$, body mass index; $\mathrm{Cl}$, confidence interval. 
and weight control behaviors among US high school students. Of the students who responded, $61.9 \%$ were white, $14.6 \%$ black, and $15.1 \%$ Hispanic. Approximately half of the students were female $(49.5 \%)$. Students were distributed by grade as follows: $29.1 \%$ in 9 th grade, $25.9 \%$ in 10 th grade, $23.3 \%$ in 11 th grade, and $21.7 \%$ in 12th grade. Nearly one-quarter $(23.0 \%, 95 \% \mathrm{CI} \pm 2.3)$ reported current cigarette use. Just under one-third described themselves as slightly $(26.9 \%, 95 \% \mathrm{CI} \pm 0.9)$ or very overweight $(4.6 \%$, $95 \% \mathrm{CI} \pm 0.6)$. However, $15.7 \%(95 \% \mathrm{CI} \pm 0.9)$ were at risk for becoming overweight, and $13.1 \%(95 \%$ $\mathrm{CI} \pm 0.9)$ were overweight. Almost half $(45.6 \%)$ were trying to lose weight. Of the 5 weight control behaviors examined, exercising was the most commonly reported $(60.0 \%, 95 \% \mathrm{CI} \pm 1.4)$, followed by ate less food, fewer calories, or foods low in fat $(40.7 \%, 95 \%$ $\mathrm{CI} \pm 1.2$ ). Vomited or took laxatives was the least frequently reported weight control behavior during the past 30 days $(4.5 \%, 95 \% \mathrm{CI} \pm 0.5)$.

Table 2 presents the prevalence and AORs of current cigarette use by demographic characteristics and weight control behaviors among US 9th -12 th grade students. Trying to lose weight was associated with current cigarette use in Model 1 (without adjusting for the 5 weight control behaviors), but not in Model 2 (after adjusting for the 5 weight control behaviors). In Model 1, students who were trying to lose weight had higher odds of current cigarette use than students not trying to lose weight ( $\mathrm{AOR}=1.3,95 \% \mathrm{CI}: 1.2-1.5)$. In Model 2, no significant association was found between current cigarette use and the 2 healthy weight control

Table 2. Prevalence and Adjusted Odds Ratios (AOR) of Current Cigarette Use* by Demographic Characteristics and Weight Control Behaviors Among 9th-12th Grade Students - United States, 2005

\begin{tabular}{|c|c|c|c|}
\hline & $\%(95 \% \mathrm{Cl})$ & $\begin{array}{l}\text { Model } 1^{\dagger} \text { AOR }(95 \% \mathrm{Cl}) \\
\text { AOR }(95 \% \mathrm{Cl})\end{array}$ & $\begin{array}{l}\text { Model } 2^{\ddagger} \text { AOR }(95 \% \mathrm{Cl}) \\
\text { AOR }(95 \% \mathrm{CI})\end{array}$ \\
\hline \multicolumn{4}{|l|}{ Demographic characteristics } \\
\hline \multicolumn{4}{|l|}{ Sex } \\
\hline Female & $23.0(20.4-25.8)$ & $1.0(0.9-1.1)$ & $0.9(0.8-1.0)$ \\
\hline Male & $23.0(20.7-25.3)$ & referent & referent \\
\hline \multicolumn{4}{|l|}{ Race/ethnicity } \\
\hline White ${ }^{\S}$ & $25.9(23.0-29.2)$ & referent & referent \\
\hline Black $^{\S}$ & $12.9(11.1-14.8)$ & $0.4(0.3-0.5)$ & $0.4(0.3-0.5)$ \\
\hline Hispanic & $22.0(18.7-25.8)$ & $0.8(0.6-1.1)$ & $0.8(0.6-1.1)$ \\
\hline Other & $19.4(15.4-24.1)$ & $0.7(0.5-0.9)$ & $0.7(0.5-1.0)$ \\
\hline \multicolumn{4}{|l|}{ Grade } \\
\hline $9^{\text {th }}$ & $19.7(17.5-22.1)$ & referent & referent \\
\hline $10^{\text {th }}$ & $21.4(18.4-24.8)$ & $1.1(0.9-1.3)$ & $1.1(0.9-1.3)$ \\
\hline $11^{\text {th }}$ & $24.3(21.2-27.7)$ & $1.3(1.1-1.5)$ & $1.3(1.1-1.5)$ \\
\hline $12^{\text {th }}$ & $27.6(24.0-31.5)$ & $1.5(1.2-1.8)$ & $1.5(1.3-1.8)$ \\
\hline \multicolumn{4}{|l|}{ BMl } \\
\hline Underweight & $24.4(18.4-31.6)$ & $1.2(0.8-1.7)$ & $1.3(0.9-1.9)$ \\
\hline Risk of underweight & $21.1(17.2-25.7)$ & $0.9(0.7-1.2)$ & $0.9(0.7-1.2)$ \\
\hline Normal weight & $21.8(19.5-23.3)$ & referent & referent \\
\hline Risk of overweight & $26.3(23.3-29.7)$ & $1.3(1.2-1.5)$ & $1.3(1.2-1.5)$ \\
\hline Overweight & $25.0(21.1-29.4)$ & $1.2(1.0-1.6)$ & $1.3(1.0-1.7)$ \\
\hline \multicolumn{4}{|l|}{ Perceived weight } \\
\hline Very underweight & $23.7(17.9-30.8)$ & $1.3(0.8-1.9)$ & $1.0(0.6-1.6)$ \\
\hline Slightly underweight & $23.0(20.2-26.0)$ & $1.1(1.0-1.3)$ & $1.1(0.9-1.2)$ \\
\hline About the right weight & $21.6(19.3-24.1)$ & referent & referent \\
\hline Slightly overweight & $25.2(22.2-28.5)$ & $0.9(0.8-1.1)$ & $0.9(0.7-1.0)$ \\
\hline Very overweight & $26.5(21.4-32.4)$ & $0.9(0.7-1.3)$ & $0.8(0.6-1.1)$ \\
\hline Trying to lose weight & $25.6(22.9-28.6)$ & $1.3(1.2-1.5)$ & $1.1(0.9-1.3)$ \\
\hline \multicolumn{4}{|l|}{ Weight control behaviors } \\
\hline Exercised"l & $23.6(21.3-26.2)$ & $\mathrm{Nl}$ & $0.9(0.7-1.1)$ \\
\hline Ate less food, fewer calories, or foods low in fatll & $26.4(23.6-29.4)$ & $\mathrm{Nl}$ & $1.0(0.9-1.1)$ \\
\hline Went without eating for $\geq 24$ hours 1 & $42.2(37.3-47.3)$ & $\mathrm{NI}$ & $2.3(2.0-2.8)$ \\
\hline Took diet pills, powders, or liquids"l & $48.3(43.0-53.6)$ & $\mathrm{Nl}$ & $2.1(1.6-2.8)$ \\
\hline Vomited or took laxatives" & $50.8(44.1-57.5)$ & $\mathrm{Nl}$ & $2.1(1.5-2.7)$ \\
\hline $\begin{array}{l}\text { *Smoked cigarettes on } \geq 1 \text { of the } 30 \text { days preceding } \\
{ }^{\dagger} \text { To lose weight or to keep from gaining weight durin } \\
\text { ₹Association of the } 5 \text { weight control behaviors with cl } \\
\text { § Non-Hispanic. } \\
\text { "Association of trying to lose weight with current ciga } \\
\text { BMI, body mass index; Cl, confidence interval; NI, not } \\
\text { Significant AORs are in bold. }\end{array}$ & $\begin{array}{l}\text { eding the survey. } \\
\text { e, controlling for try } \\
\text { ntrolling for sex, rac }\end{array}$ & $\begin{array}{l}\text { e weight, sex, race/ethnicity, gr } \\
\text { ity, grade, perceived weight, an }\end{array}$ & $\begin{array}{l}\text { eived weight, and BMI category. } \\
\text { gory. }\end{array}$ \\
\hline
\end{tabular}


behaviors: eating less food, fewer calories, or foods low in fat $(A O R=1.0,95 \%$ CI: $0.9-1.1)$ or exercising (AOR $=0.9,95 \% \mathrm{CI}: 0.7-1.1)$. Each of the 3 unhealthy weight control behaviors was significantly associated with current cigarette use. Compared with students who did not engage in the behavior, the odds of current cigarette use were higher among students who went without eating for $\geq 24$ hours $(\mathrm{AOR}=2.3$, 95\% CI: 2.0-2.8); took diet pills, powders, or liquids (AOR=2.1, 95\% CI: 1.6-2.8); and vomited or took laxatives (AOR $=2.1,95 \% \mathrm{CI}: 1.5-2.7$ ).

Table 3 reports Wald chi-square $\left(\chi^{2}\right)$ and p-values for interactions of sex, race/ethnicity, and grade with trying to lose weight and weight control behaviors in association with current cigarette use. None of the interaction terms tested were statistically significant, indicating the associations between trying to lose weight and the 5 weight control behaviors with current cigarette use did not vary statistically by sex, race/ethnicity, or grade.

Table 3. Wald Chi-Square $\left(\chi^{2}\right)$ and $p$-Value for Interactions of Sex, Race/Ethnicity, and Grade With Trying to Lose Weight and Weight Control Behaviors in Association With Current Cigarette Use* Among 9th-12th Grade Students-United States, 2005

\begin{tabular}{lc}
\hline Interaction Term & $\begin{array}{c}\text { Interaction Term }{ }^{\dagger} \text { Wald } \\
\mathbf{\chi}^{\mathbf{2}} \text { (p-value) }\end{array}$ \\
\hline $\begin{array}{l}\text { Trying to lose weight } \\
\times \text { Sex }\end{array}$ & \\
$\times$ Race/ethnicity & $0.01(0.91)$ \\
$\times$ Grade & $0.09(0.96)$ \\
Exercised & $0.11(0.95)$ \\
$\times$ Sex & \\
$\times$ Race/ethnicity & $0.21(0.65)$ \\
$\times$ Grade & $1.00(0.40)$ \\
Ate less food, fewer calories, or foods lowin & $0.51(0.68)$ \\
$\quad$ fat ${ }^{\ddagger}$ & \\
$\times$ Sex & \\
$\times$ Race/ethnicity & $0.05(0.83)$ \\
$\times$ Grade & $1.35(0.27)$ \\
Went without eating for $\geq 24$ hours $^{\ddagger}$ & $0.84(0.48)$ \\
$\times$ Sex & \\
$\times$ Race/ethnicity & $0.01(0.94)$ \\
$\times$ Grade & $1.01(0.40)$ \\
Took diet pills, powders, or liquids ${ }^{\ddagger}$ & $0.72(0.55)$ \\
$\times$ Sex & \\
$\times$ Race/ethnicity & $1.23(0.27)$ \\
$\times$ Grade & $2.39(0.08)$ \\
Vomited or took laxatives ${ }^{\ddagger}$ & $0.56(0.65)$ \\
$\times$ Sex & \\
$\times$ Race/ethnicity & \\
$\times$ Grade & $0.71(0.40)$ \\
\hline
\end{tabular}

*Smoked cigarettes on $\geq 1$ of the days preceding the survey.

${ }^{+}$Interaction terms added to Model 2, which included the main effects of sex, race/ethnicity, grade, body mass index category, perceived weight, trying to lose weight, the 2 healthy weight control behaviors, and the 3 unhealthy weight control behaviors.

${ }^{\ddagger}$ To lose weight or to keep from gaining weight during the 30 days preceding the survey.

\section{DISCUSSION}

Trying to lose weight was associated with current cigarette use before, but not after, adjusting for healthy and unhealthy weight control behaviors. When the model controlled for trying to lose weight, students who engaged in unhealthy weight control behaviors, but not healthy weight control behaviors, were more likely to report current cigarette use. These findings suggest that trying to lose weight per se is not a risk factor for current cigarette use. In fact, students who are engaging in healthy weight control behaviors (ie, exercising or eating less food, fewer calories, or foods low in fat) are no more likely to currently use cigarettes than students who are not engaging in these behaviors. However, students who engage in unhealthy weight control behaviors (ie, went without eating for $\geq 24$ hours; took diet pills, powders, or liquids; or vomited or took laxatives) were more likely to currently use cigarettes than students who did not engage in the behaviors.

This study is 1 of the first to examine systematically whether trying to lose weight is independently associated with current cigarette use and to examine the association of specific healthy and unhealthy weight loss behaviors with current cigarette use, while controlling for perceived body weight and BMI category. The results of this study indicate that the association of unhealthy weight control behaviors with cigarette use is significant regardless of students' BMI or perceived body weight. Although previous research has documented significant differences by sex and race/ethnicity, 7,13,14,17 we found that these associations did not vary by sex or race/ethnicity. The results of this study may differ from previous studies because this study included both male and female students and controlled for BMI. Additionally, previous studies may have examined only healthy or only unhealthy weight control behaviors, but not both.

This study is subject to at least 2 limitations. Data are based on self-report and the extent of underreporting and overreporting of behaviors cannot be determined; however, the survey questions have been shown to demonstrate good test-retest reliability. ${ }^{22}$ In addition, data are cross-sectional and causality cannot be inferred.

The results from this study have direct implications for interventions designed to promote healthy weight among adolescents. School health curricula that promote healthy weight control should incorporate education on healthy weight loss strategies and emphasize the negative health consequences of cigarette smoking. In addition, it may be important to incorporate smoking prevention messages into existing weight management interventions, health curricula, and educational materials, especially those that target adolescents who 
use unhealthy weight control practices. A first step toward this is increasing awareness among school health educators and health care providers of the use by adolescents of smoking for weight loss.

In light of our findings, it also may be important to identify whether smoking cessation programs have unanticipated consequences, such as increasing the risk of unhealthy weight control practices. If adolescents who smoke to lose weight are also prone toward using other unhealthy weight control practices, then they might be at increased risk for other unhealthy weight control behaviors if they successfully quit smoking. As such, it may be appropriate to incorporate healthy weight control education into smoking cessation programs.

Further research is needed to examine the behavioral determinants and factors underlying the association between unhealthy weight control practices and cigarette smoking, and should examine whether these associations vary by sex or race/ethnicity, as has been documented in previous studies. 8,14

\section{REFERENCES}

1. Centers for Disease Control and Prevention. Trends in cigarette smoking among high school students-United States, 1991-2005. MMWR Morb Mortal Wkly Rep. 2006;55(26): 724-726.

2. Centers for Disease Control and Prevention. Youth risk behavior surveillance, United States-2005. MMWR Morb Mortal Wkly Rep. 2006;55(SS05): 1-112.

3. US Department of Health and Human Services. Healthy People 2010. 2nd ed. 2 vols. With Understanding and Improving Health and Objectives for Improving Health. Washington, DC: US Government Printing Office; 2000;1-62.

4. Strauss RS, Mir HM. Smoking and weight loss attempts in overweight and normal-weight adolescents. Int $J$ Obes Relat Metab Disord. 2001;25(9): 1381-1385.

5. Tomeo CA, Field AE, Berkey CS, Colditz GA, Frazier AL. Weight concerns, weight control behaviors, and smoking initiation. Pediatrics. 1999;104(4 Pt 1):918-924.

6. Camp DE, Klesges RC, Relyea G. The relationship between body weight concerns and adolescent smoking. Health Psychol. 1993;12(1):24-32.

7. Lowry R, Galuska DA, Fulton JE, Wechsler H, Kann L. Weight management goals and practices among US high school students: associations with physical activity, diet, and smoking. $J$ Adolesc Health. 2002;31:133-144.

8. Cavallo DA, Duhig AM, McKee S, Krishnan-Sarin S. Gender and weight concerns in adolescent smokers. Addict Behav. 2006;31(11):2140-2146.

9. Delveno CD, Hrywna M, Abatemarco DJ, Lewis MJ. Relationships between cigarette smoking and weight control in young women. Fam Community Health. 2003;26(2): 140-146.

10. Boles SM, Johnson PB. Gender, weight concerns, and adolescent smoking. J Addict Dis. 2001;20(2):5-14.

11. Potter BK, Pederson LL, Chan SSH, Aubut JL, Koval JJ. Does a relationship exist between body weight, concerns about weight, and smoking among adolescents? An integration of the literature with an emphasis on gender. Nicotine Tob Res. 2004;6(3):397-425.

12. Neumark-Sztainer D, Hannan PJ. Weight-related behaviors among adolescent girls and boys: results from a national survey. Arch Pediatr Adolesc Med. 2000;154(6):569-577.

13. Page RM, Allen O, Moore L, Hewitt C. Weight related concerns and practices of male and female adolescent smokers and nonsmokers. J Health Educ. 1993;24:339-346.

14. Fulkerson JA, French SA. Cigarette smoking for weight loss or control among adolescents: gender and racial. Ethnic differences. $J$ Adolesc Health. 2003;32:306-313.

15. Neumark-Sztainer D, Story M, French SA. Covariations of unhealthy weight loss behaviors and other high-risk behaviors among adolescents. Arch Pediatr Adolesc Med. 1996;150(3): 304-308.

16. Krowchuck DP, Kreiter SR, Woods CR, Sinal SH, DuRant RH. Problem dieting behaviors among young adolescents. Arch Pediatr Adolesc Med. 1998;152(9):884-888.

17. Winter AL, de Guia NA, Ferrence R, Cohen JE. The relationship between body weight perceptions, weight control behaviors and smoking status among adolescents. Can J Public Health. 2002;93(5):362-365.

18. Eaton DK, Kann L, Kinchen S, et al. Youth risk behavior surveillance-United States 2005. J Sch Health. 2006;76(7): 353-372.

19. Brener N, Kann L, Kinchen S, et al. Methodology of the youth risk behavior surveillance system. MMWR Morb Mortal Wkly Rep. 2004;53(RR-12): 1-13.

20. Kuczmarski RJ, Ogden CL, Grummer-Strawn LM, et al. CDC growth charts: United States. Adv Data. 2000;314:1-28.

21. Shah BV, Barnwell BG, Bieler GS. SUDAAN User's Manual, Release 7.0 Version. Research Triangle Park, NC: Research Triangle Institute, 1996.

22. Brener N, Kann L, McManus TL, Kinchen S, Sundberg EC, Ross JG. Reliability of the 1999 Youth Risk Behavior Survey questionnaire. $J$ Adolesc Health. 2002;31:336-342. 